\title{
ANÁLISE DO EQUILIIBRIO ESTÁTICO EM DIFERENTES DÉCADAS DE VIDA EM MULHERES ADULTAS E IDOSAS
}

\author{
Guilherme Carlos Brech; guibrech@gmail.com; Universidade São Judas Tadeu \\ Michele Figueira Nunes; michelefnunes@yahoo.com.br; Universidade São Judas Tadeu \\ Tatiana Godoy Bobbio; TBobbio@usa.edu ; University of St. Augustine for Health Sciences, Miami \\ Campus, FL/ United States of America.
}

Gabriela Perez; gperez@usa.edu ; University of St. Augustine for Health Sciences, Miami Campus, FL/ United States of America. Kelem de Negreiros Cabral; kelemcabra!@hotmail.com; Faculdade de Medicina da Universidade de São Paulo Luiz Eugênio Garcez Leme; lueglem@usp.br ; Faculdade de Medicina da Universidade de São Paulo Julia Maria D'Andréa Greve; jgreve@usp.br; Faculdade de Medicina da Universidade de São Paulo Angélica Castilho Alonso; angelicacastilho@msn.com; Universidade São Judas Tadeu

\section{RESUMO}

Introdução: Uma das alterações inerentes ao processo de envelhecimento, é a piora do equilíbrio postural. Objetivo: Analisar o equilíbrio estático em mulheres durante processo de envelhecimento, e compará-lo entre as diferentes faixas etárias a partir dos 50 anos. Método: Trata-se de um estudo transversal, observacional, participaram do estudo 394 mulheres, agrupadas conforme a faixa etária, por décadas. Sendo 58 mulheres entre os 50 e 59 anos (6a década); 214 com idade entre 60 e 69 anos ( 7 a década); 90 com idade entre 70 e 79 anos (8a década) e 36 com mais de 80 anos (9a década). A avaliação do equilíbrio estático foi realizada em plataforma de força portátil com três medidas com os olhos abertos (OA) e fechados (OF), 60 segundos cada. Resultados: Nas duas condições de medição, as idosas na $9^{a}$ década apresentaram deslocamento e amplitude médio-lateral e velocidade superiores aos valores da $6^{\text {a }}$ e 7ª década. Na condição OA, o deslocamento médio-lateral foi maior na $9^{\underline{a}}$ década em relação à $6^{\underline{a}}$ e $7^{\text {a }}$ décadas, ântero-posterior apenas na amplitude da $6^{\text {a à }} 9^{\underline{a}}$ década. Ainda na situação OA, as idosas do grupo da $9^{\underline{a}}$ década tiveram maior

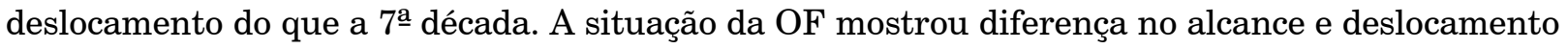
na direção médio-lateral, da $6^{\text {o }}$ e $7^{\mathbf{0}}$ décadas à $9^{\mathbf{a}}$ décadas. Conclusão: A posturografia mostrou declínio do equilíbrio postural com o avançar da idade. Sugerindo que a 9a década de vida é uma idade limítrofe a este detrimento devido ao aumento da instabilidade postural.

Palavras-chave: Envelhecimento; Equilíbrio estático; Risco de quedas; Posturografia.

Agradecimentos: "O presente trabalho foi realizado com apoio da Coordenação de Aperfeiçoamento de Pessoal de Nível Superior - Brasil (CAPES) - Código de Financiamento 001”. 